\title{
Review of genetic factors in intestinal malrotation
}

\author{
Vicki Martin · Charles Shaw-Smith
}

Accepted: 16 May 2010/Published online: 13 June 2010

(C) The Author(s) 2010. This article is published with open access at Springerlink.com

\begin{abstract}
Intestinal malrotation is well covered in the surgical literature from the point of view of operative management, but few reviews to date have attempted to provide a comprehensive examination of the topic from the point of view of aetiology, in particular genetic aetiology. Following a brief overview of molecular embryology of midgut rotation, we present in this article instances of and case reports and case series of intestinal malrotation in which a genetic aetiology is likely. Autosomal dominant, autosomal recessive, X-linked and chromosomal forms of the disorder are represented. Most occur in syndromic form, that is to say, in association with other malformations. In many instances, recognition of a specific syndrome is possible, one of several examples discussed being the recently described association of intestinal malrotation with alveolar capillary dysplasia, due to mutations in the forkhead box transcription factor FOXF1. New advances in sequencing technology mean that the identification of the genes mutated in these disorders is more accessible than ever, and paediatric surgeons are encouraged to refer to their colleagues in clinical genetics where a genetic aetiology seems likely.
\end{abstract}

Keywords Intestinal malrotation $\cdot F O X F 1 \cdot$ Genetics Embryology

\footnotetext{
V. Martin · C. Shaw-Smith

Wellcome Trust Sanger Institute, Hinxton,

Cambridge CB10 1SA, UK

V. Martin · C. Shaw-Smith ( $₫)$

Institute of Child Health, 30 Guilford Street,

London WC1N 1EH, UK

e-mail: css@sanger.ac.uk
}

\section{Introduction}

The significance and potential seriousness of intestinal malrotation is well appreciated by paediatric surgeons. Reviews of the subject in the surgical literature focus on surgical treatment of the disorder and the prevention of complications [1-4]. Few reviews to date have attempted to treat the subject from the point of view of aetiology and classification, but our improving knowledge of genetics in both humans and model organisms means that it is reasonable now to try to undertake a systematic review of those conditions in which intestinal malrotation has been described as a component. This type of approach is the one favoured by clinical geneticists, for whom an understanding of the precise cause of a malformation is essential to their task of advising families of the likelihood of a recurrence of the same condition in future offspring. For other malformations such as oesophageal atresia, recurrence risk data have been provided [5], but not for intestinal malrotation, to the authors' knowledge.

In conducting this review, we have collected together as comprehensively as possible all clinical reports of intestinal malrotation where the suggestion of a genetic aetiology is made. This might be because of apparent autosomal dominant or autosomal recessive transmission, parental consanguinity of sibling recurrence; because of association with a chromosomal imbalance; or because of the combination of features in addition to intestinal malrotation is suggestive of a syndrome with a possible genetic aetiology. This review is preceded by a brief survey of our knowledge of the embryology of midgut rotation, with particular reference to those genes which have been shown to have a role in the process. 
Fig. 1 Transverse sections showing schema for development of mesodermal germ layer and gut tube. a Day 17, b day 19, c day 20, d day 21. The thin mesodermal sheet gives rise to paraxial mesoderm (future somites), intermediate mesoderm (future excretory units) and the lateral plate, which divides into parietal and visceral layers lining the intra-embryonic body cavity. e Day 25 (approx), f day 30 (approx). g Dorsal mesoderm shows leftward tilt. Timing of this event in humans is currently not known. At the end of the fourth week, visceral mesoderm layers are fused in the midline and form a doublelayered membrane (dorsal mesentery) between right and left halves of the body cavity. Redrawn from Langman's Medical Embryology 11th Edition, Sadler TW, Figure 6.8, page 75 and Figure 14.3, page 211, with permission

\section{Embryology of midgut rotation: correlation of morphological change with molecular events}

Recently, an understanding of the molecular events guiding early development and rotation of the midgut has begun to emerge, with a key role for the dorsal mesentery in generating the left-right asymmetry that allows rotation to take place. The process of midgut formation from trilaminar germ disc to final position of the gut tube is depicted in Fig. 1.

The key event leading to formation of the dorsal mesentery is the division of the lateral plate mesoderm into its somatic and splanchnic components, creating the coelom or body cavity, at around weeks 3-4 of gestation (Fig. 1a-g). The forkhead box transcription factor Foxfl plays a key role in this process. Division of the lateral plate mesoderm is disrupted in mice with targeted knock-out of Foxfl [6], with somatic and splanchnic layers either remaining fused together, or with residual points of attachment leading to incomplete separation (Fig. 2a-d).

Following division of the lateral plate mesoderm, Foxfl expression normally becomes restricted to the splanchnic mesoderm; activation of the homeobox gene Irx3, another marker for lateral plate differentiation, becomes restricted to the somatic mesoderm. In Foxf1 null mice, Irx3 expression is detectable in both somatic and splanchnic mesoderm, suggesting that its expression is normally inhibited by Foxfl.

Recently, initiation of intestinal rotation has been shown to be mediated by key ultrastructural changes in the dorsal mesentery [7]. Mesenchymal cells on the right side of the mesentery become more sparse and assume a cuboidal appearance, while those on the left side become more densely packed and assume a columnar appearance. As a consequence of this, the dorsal mesentery acquires a tilt to the left (Fig. 3a, b). This sequence of events is under the molecular control of two transcription factors, Pitx 2 and Isll. These genes are themselves asymmetrically expressed on the left side of the mesentery, under control of Nodal, whose expression in the left lateral plate mesoderm is the initial symmetry-breaking event in the embryo.

Following tilting of the dorsal mesentery, rapid elongation of the intestine after week 5 combined with rapid
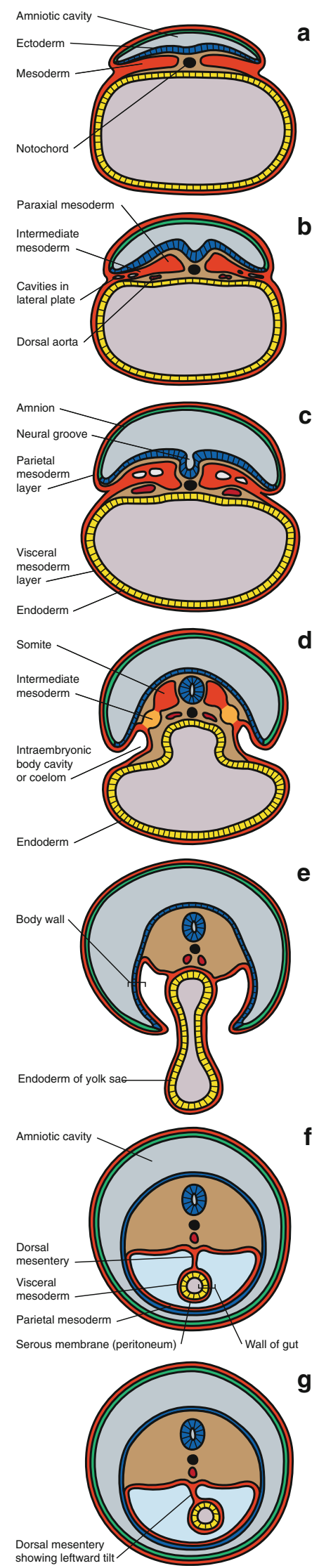


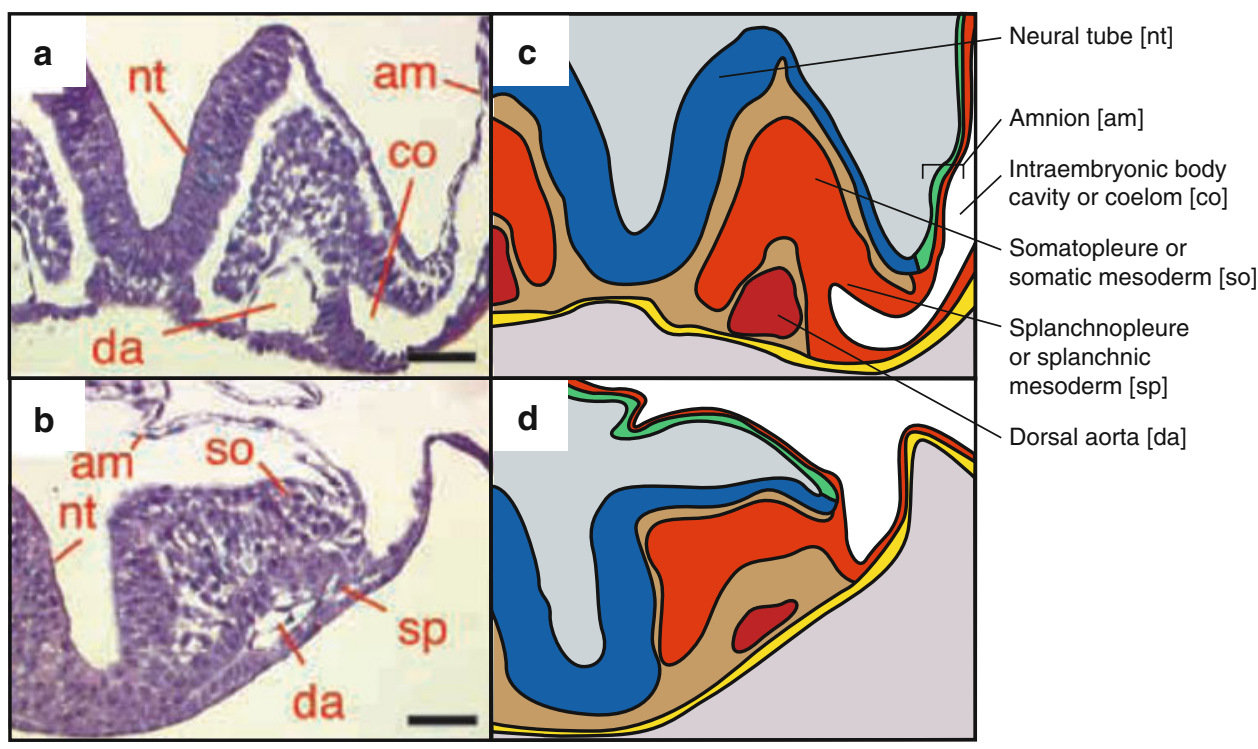

Fig. 2 Requirement of normal Foxf1 function for lateral plate differentiation and coelom formation. Differentiation of somatopleure and splanchnopleure and the associated formation of the coelomic cavity is disturbed in Foxf1-/- embryos. a, c Wildtype, b, d Foxf1-/- embryo at mouse embryonic day 8.5. Separation of the somatic and splanchnic mesodermal layers is incomplete in the
Foxf1-1- embryo, and formation of the coelomic cavity is disrupted, with failure of the coelomic cavity to invade the lateral plate mesoderm. nt neural tube, $d a$ dorsal aorta, co coelom, am amnion, so somatic mesoderm or somatopleure, $s p$ splanchnic mesoderm or splanchnopleure. Reproduced from Ref. [6], Figure 8, page 163, with permission a

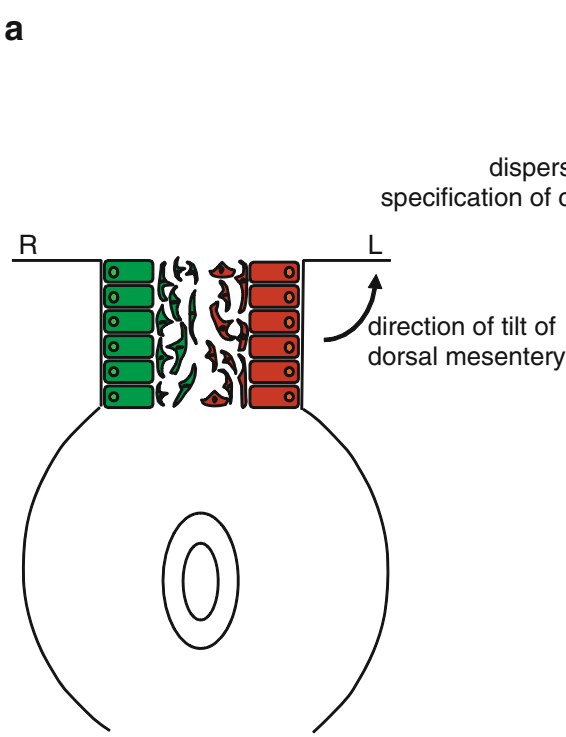

Fig. 3 Model for the directional looping of the gut tube. See text for additional explanation. a Initially, the gut tube is suspended symmetrically from the dorsal mesentery within the body cavity. $\mathbf{b}$ Subsequently, expression of the transcription factors Pitx2 and Isl under the influence of Nodal is restricted to the left side, and of Tbx18 to the right. This results in morphological changes to the epithelium and mesenchyme of the mesentery: columnar epithelium on the left as opposed to cuboidal on the right, and aggregation of mesenchymal

growth and expansion of the liver results in temporary herniation of the intestinal loops of the midgut into the umbilical cord [1]. Coincident with this growth, the small b

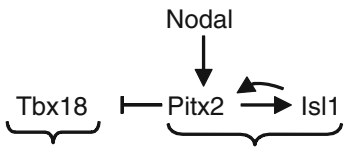

aggregation of mesenchyme

specification of columnar epithelium

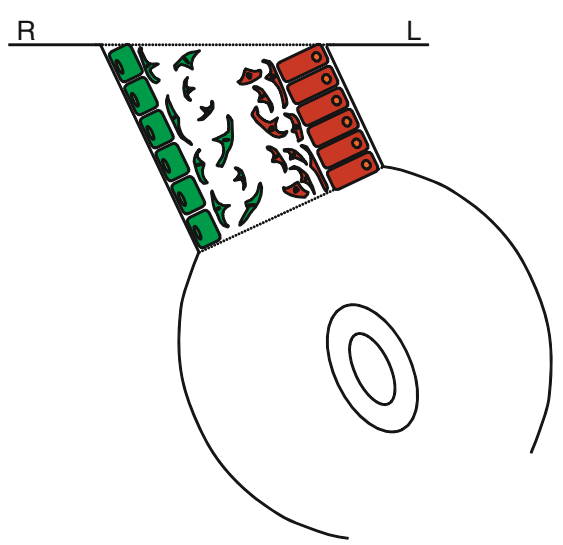

cells on the left as opposed to dispersal on the right. The result of these changes is a leftward tilt of the dorsal mesentery, which consequently takes on a trapezoidal rather than a rectangular shape. These studies were performed in the chick embryo, stage HH20-22 (Hamburger and Hamilton [56]), corresponding to mouse embryonic day 10.5-10.75. Redrawn from Davis et al. [7], Figure 7, with permission

intestine rotates around an axis formed by the superior mesenteric artery, for a total of $270^{\circ}$ in an anti-clockwise direction, the process being completed by the time of the 
Fig. 4 Normal intestinal rotation. a, b Primary intestinal loop before rotation (lateral view). The superior mesenteric artery forms the axis of the loop and of subsequent rotation. $\mathbf{c}-\mathbf{e}$ Counter-clockwise rotation of the gut occurs through $270^{\circ}$ concomitantly with herniation of the small intestinal loops followed by return of the gut to the abdominal cavity during the third month of gestation. Redrawn from Filston and Kirks [2], with permission

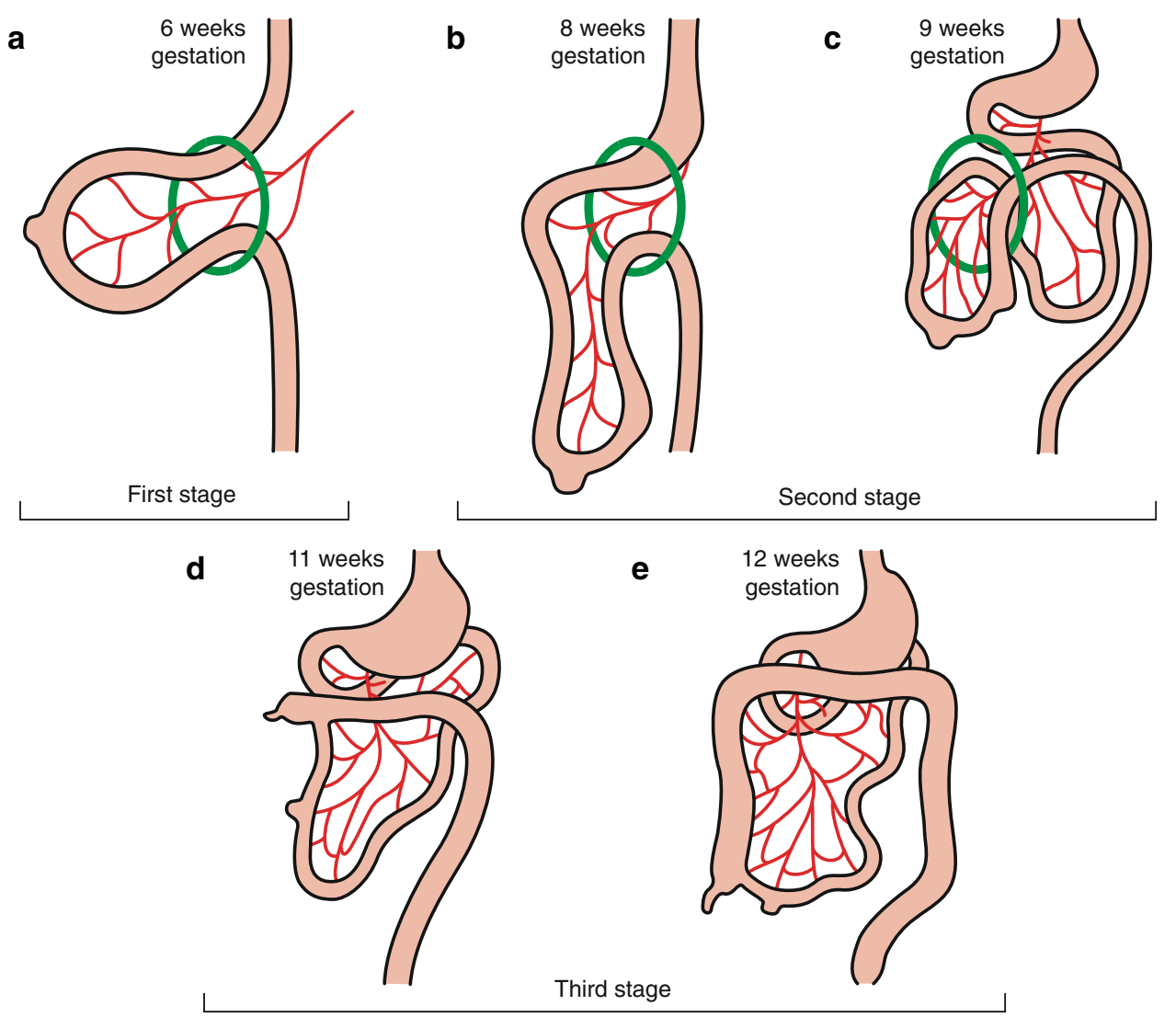

return of the intestine to the abdominal cavity during the 10th week (Fig. 4a-e).

\section{Overview of intestinal malrotation}

The incidence of intestinal malrotation is generally cited in the literature to be $0.2 \%$ or 1 in $500[1,3,4]$. This figure is based on a series of 2,000 consecutive cases of roentgenographic evaluation of the colon [8], in which evidence of non-rotation of the colon was identified in 4 cases. No comparable prospective series of upper gastro-intestinal examinations exists, to the authors' knowledge. It is worth emphasizing first, that intestinal malrotation comprises a spectrum of anomalies, including 'typical', 'atypical', 'mixed' and incomplete', and second, that the figure of $0.2 \%$ includes all cases of malrotation irrespective of symptoms, and the incidence of symptomatic intestinal malrotation is likely to be somewhat lower. Both of these issues have been well discussed in a recent review [1].

There have been few attempts to provide a classification of intestinal malrotation based on aetiology, perhaps because little is known of the cause when malrotation occurs in isolation (non-syndromic), and because when it occurs in association with other malformations, such as gut atresias, short bowel, biliary or pancreatic malformations, heart defect and so on, these tend to overshadow malrotation in terms of severity and significance. The main purpose of this review is to draw attention to those instances of intestinal malrotation where the aetiology is known, or likely to be, genetic.

\section{Intestinal malrotation due to mutations in known genes}

Intestinal malrotation due to mutations in the forkhead box transcription factor FOXF1

Recently, it was shown that intestinal malrotation results from inactivating heterozygous mutations in the forkhead transcription factor FOXF1 [9]. As well as intestinal malrotation, congenital short bowel has been reported in one case. These patients have in addition a severe developmental lung abnormality termed alveolar capillary dysplasia with misalignment of pulmonary veins (ACD/MPV) in which failure of development of the intrinsic pulmonary vasculature of the lungs occurs [ 9 and references therein]. There is minimal response to supportive measures and death usually occurs within the first month of life. Malformations of the urinary tract also occur in these patients. 
The critical role of the dorsal mesentery in mediating normal rotation of the intestine and the role of Foxfl in formation of the dorsal mesentery in mice make this finding perhaps unsurprising. Curiously, intestinal malrotation has not been reported in mice with inactivation either of one or of both copies of Foxfl, although these mice do have oesophageal atresia and tracheo-oesophageal fistula [6]. It is not clear whether malrotation in these mice is truly absent or whether it has been overlooked, or not specifically sought.

It is worth noting that the clinical features occurring in patients with FOXF1 mutations have features in common with the heterotaxy syndromes described above and in Table 1. As well as intestinal malrotation, pulmonary isomerism and situs abnormalities of the great vessels occur. One patient with deletion of FOXF1 and the neighbouring MTHFSD gene had in addition absent spleen and transverse orientation of the liver, both features of heterotaxy.

Intestinal malrotation due to mutations in genes controlling $\mathrm{L}-\mathrm{R}$ patterning

Intestinal malrotation, along with complex congenital heart defect, abnormalities of lung lobation, and other abnormalities of abdominal visceral situs, is a cardinal feature of situs abnormality. A detailed treatment of this large and complex subject is beyond the scope of this review, but nonetheless a review of intestinal malrotation without some consideration of it would be incomplete.

Asymmetric placement of the thoracic and abdominal organs in the normally developed vertebrate is the rule rather than the exception. In the abdomen, the stomach, liver, spleen, small and large intestine, and biliary tract are all asymmetrically placed. In the last 10-15 years, mutations have been identified in genes with a role in specifying L-R asymmetry in the early embryo, and the clinical problems associated with these mutations have been elucidated in humans. Table 1 lists features of clinical syndromes due to mutations in L-R asymmetry genes. Only those genes for which intestinal malrotation has been described as a component of the clinical syndrome are included; a detailed review of the whole subject has been provided by Maclean and Dunwoodie [10].

\section{Intestinal malrotation: likely genetic but chromosomal locus and gene mutations not yet identified}

In this section, instances of intestinal malrotation are presented, in which familial recurrence and/or parental consanguinity point to a likely genetic aetiology.

Subdivision is made into those forms which are non-syndromic (i.e., isolated intestinal malrotation), and syndromic, in which other malformations occur, either within the GI tract or elsewhere. A summary of all of the conditions cited in the text is presented in the table.

Non-syndromic intestinal malrotation

Familial non-syndromic intestinal malrotation associated with midgut volvulus and with clear evidence for autosomal dominant inheritance was published in 1972 by Stuart L Smith, a surgeon at the Lutheran Hospital, Wheat Ridge, CO, USA [11]. Eight affected individuals, five male and three female in three generations were reported. Additional affected individuals are likely to have been born since the publication of this report, and it would be of great interest to make a further study of this family with a view to identifying the genetic lesion responsible.

A second family with possible autosomal dominant inheritance was published more recently [12], in which three siblings (two girls and one boy) presented with intestinal malrotation; barium studies in the mother, who had symptoms of constipation and vomiting, revealed 'incomplete duodenum without normal distal flexure', but not malrotation.

Syndromic intestinal malrotation

Four syndromes featuring intestinal malrotation and other GI tract malformations, as well as extra-intestinal malformations, and all with strong evidence for autosomal recessive inheritance (sibling recurrence and parental consanguinity in each) have been reported, and all appear to be distinct, although some are sufficiently similar that a common genetic aetiology should be considered a possibility. Gastro-intestinal atresias feature prominently in some of these syndromes, and indeed, the possible relationship between intestinal malrotation and gastro-intestinal tract atresias has previously been explored [13].

The first of these conditions, originally reported by Martinez-Frias [14] and recently reviewed by Chappell et al. [15], has been termed Martinez-Frias syndrome and comprises multiple gastro-intestinal atresias with malrotation in some cases, abnormalities of the biliary system (agenesis of the gall bladder, intra- and extra-hepatic biliary atresia) and pancreas (hypoplasia, agenesis, neonatal diabetes mellitus). Malrotation as well as extra-intestinal manifestations (hypospadias, congenital heart defect) has been described. Several candidate genes have been screened, but no causative mutations identified to date [15].

The second condition has been termed multiple gastrointestinal atresias. Many of the reported cases have been in the French-Canadian ethnic group [16], although a report in a kindred from Ireland exists [17]. Again, there is good evidence for autosomal recessive inheritance with sibling 


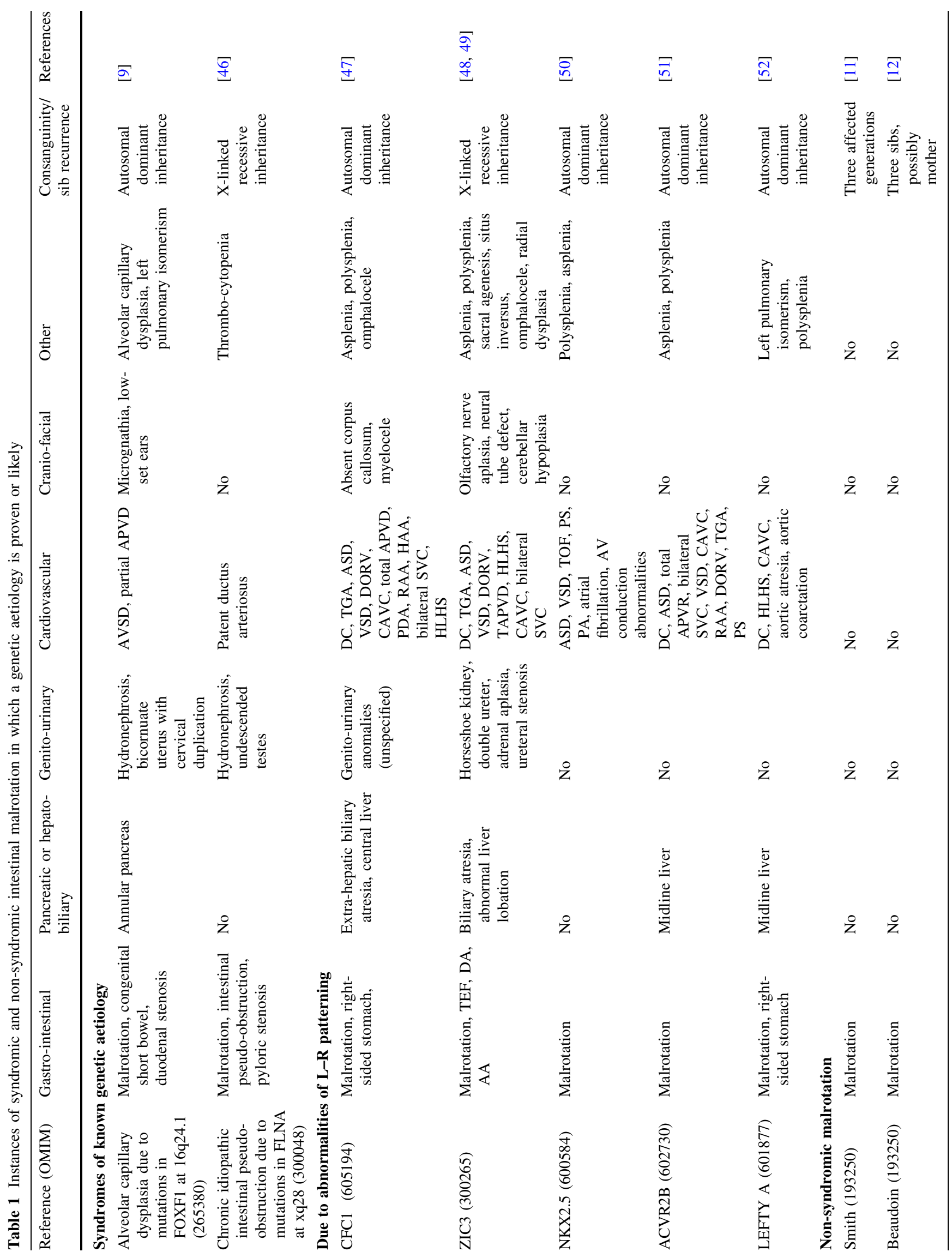




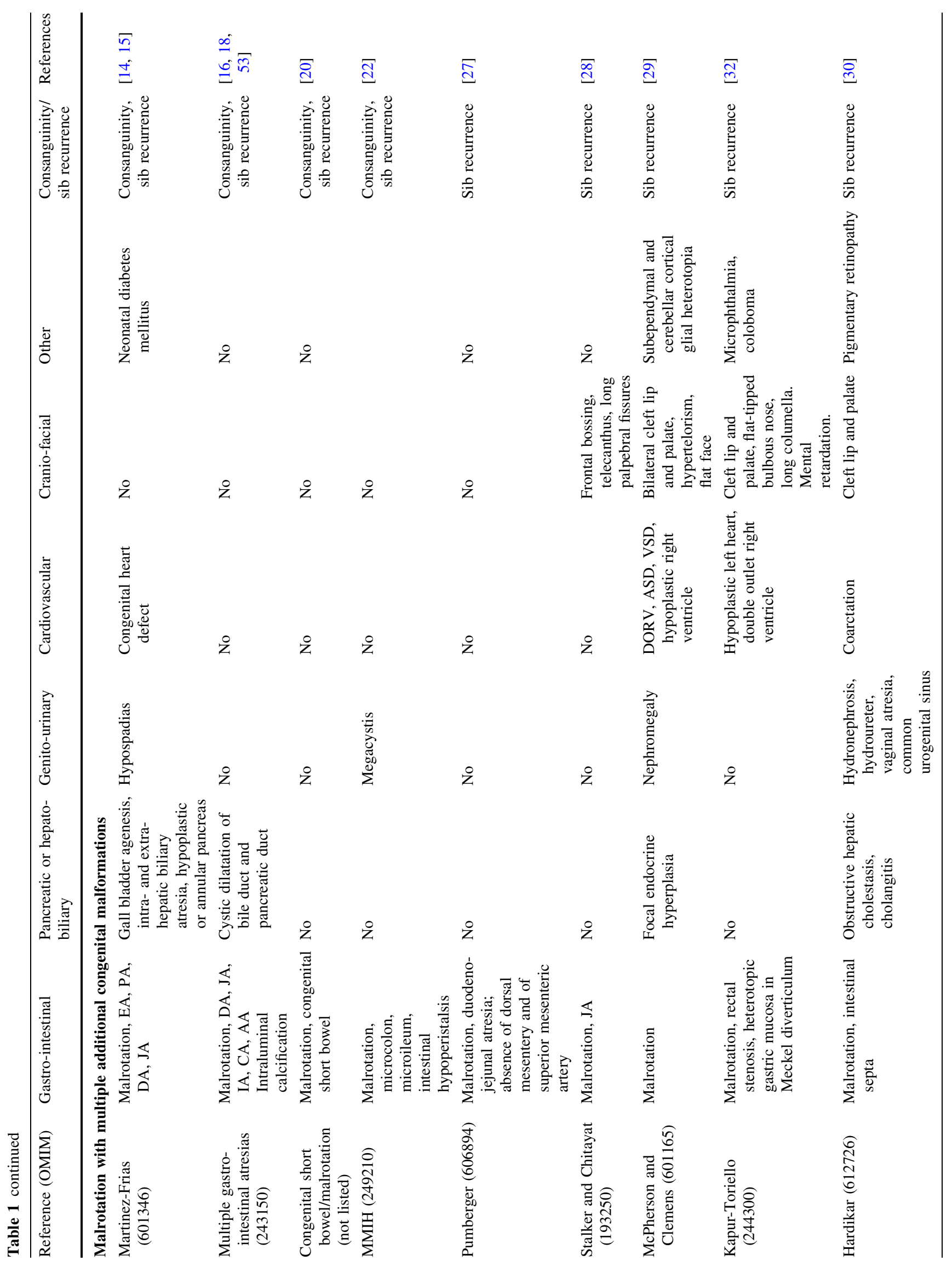




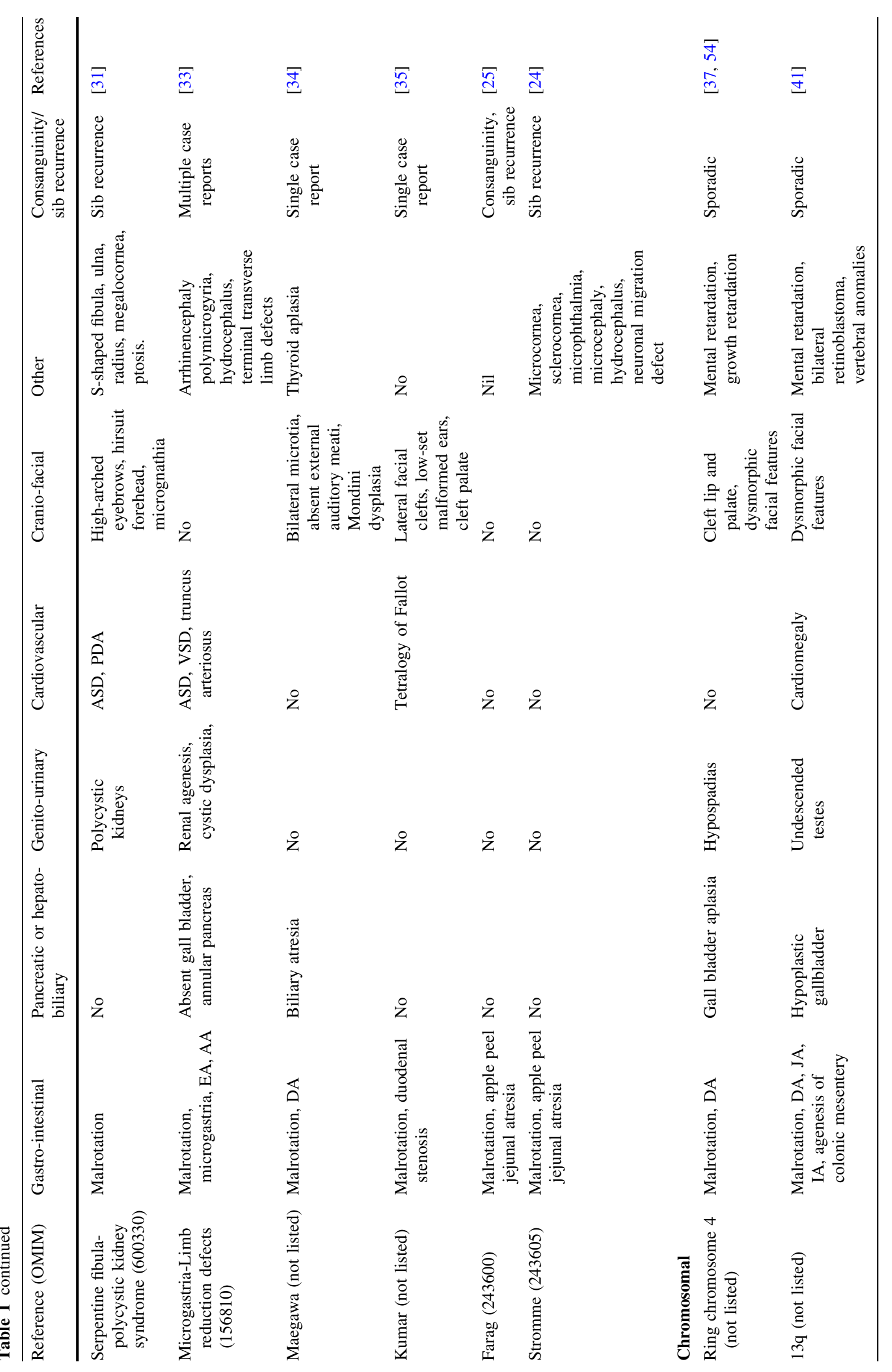




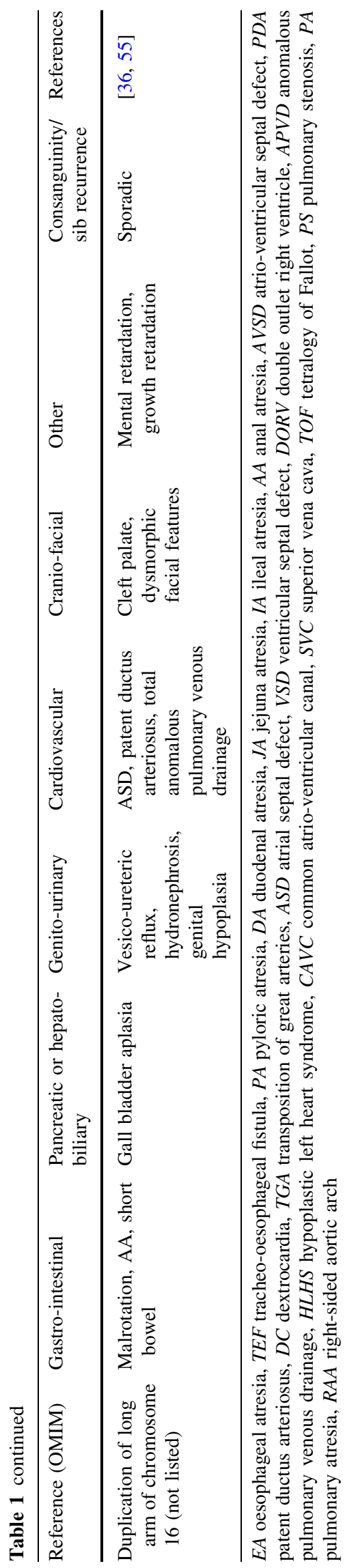

recurrence and parental consanguinity. Intraluminal calcification of intestinal contents trapped within atretic segments is characteristic of this syndrome, and this may be visible during pre-natal ultrasound, or post-natally on a plain abdominal radiograph [18]. Cystic dilation of pancreatic and biliary ductal systems occurs and is probably secondary to impaired drainage into a blind duodenal loop. Extra-intestinal manifestations are rare. In a review of 18 cases, death occurred in infancy in each instance [19].

The combination of intestinal malrotation and short bowel has been reported. The best documented example is a kindred from Israel, featuring six affected individuals, again with consanguinity and sibling recurrence [20], but there are other instances in the literature [21]. In the Israeli kindred, very short bowel (range 35-51 cm) was observed in three individuals who died in infancy; a surviving child had a bowel length of $95 \mathrm{~cm}$, with malrotation and two other surviving individuals had, at the time of the report, avoided surgery, but did have malrotation and short bowel documented by barium meal examination. Extra-intestinal manifestations do not appear to be a feature of this condition.

The syndrome of Megacystis, Microcolon and Intestinal Hypoperistalsis (MMIH) is well-documented with many reports in the literature, including many instances of parental consanguinity and sibling recurrence. A detailed review was provided by Anneren et al. [22]. Intestinal malrotation is a common feature. The condition appears to be a disorder of hollow viscera only, with no abnormalities outside these organs. Mice lacking the beta2 and beta4 subunits of the neuronal nicotinic acetyl choline receptor have a phenotype resembling this disorder [23], but mutations in these genes have to date not been identified in patients with it.

There are two apparently distinct autosomal recessive disorders featuring 'apple peel' atresia in association with intestinal malrotation. In this rare form of atresia, there is significant loss of bowel length and small intestinal atresia; the small intestine curls around the superior mesenteric artery giving the impression of an apple peel [24]. Other descriptive terms include 'Christmas tree', 'pagoda', and 'maypole' [25]. Farag et al. [25] reported a consanguineous family with four affected sibs, and reviewed the literature, which contains several similar families [26]. In these families, the bowel abnormality is isolated with no other intestinal or extra-intestinal malformations.

In the second disorder featuring apple peel atresia, extraintestinal manifestations do occur, specifically microcephaly and ocular anomalies (microphthalmia; anterior eye chamber anomalies: corneal opacities, iris hypoplasia, adhesions between iris and cornea). van Bever and others reported a patient and reviewed the literature. Autosomal recessive inheritance is possible based on one report of sibling recurrence [24]. 
There are several less well-documented and rarer entities featuring syndromic intestinal malrotation with sibling recurrence, but without parental consanguinity. Pumberger et al. [27] reported the combination of duodenal atresia, malrotation, absent dorsal mesentery and absent superior mesenteric artery in four individuals, two of whom were sisters, and argued that this is distinct from the more commonly recognized apple peel small bowel atresia. Stalker and Chitayat [28] described intestinal malrotation and facial anomalies (high forehead, long palpebral fissures) in two sisters. McPherson and Clemens [29] reported the combination of bilateral cleft lip and palate with severe congenital heart defect and central nervous system abnormalities in a brother and sister. Hardikar syndrome [30] is reasonably well-characterized, with obstructive liver and biliary tract disease, intestinal malrotation, obstructive uropathy, congenital heart defect, cleft lip and palate, and a characteristic ('cats paw') retinopathy. In serpentine fibula syndrome [31], characteristic skeletal manifestations, other than the ' $\mathrm{S}$ '-shaped fibula, are bowing of the radius and ulna, and flattening of the vertebrae. Heart malformations and polycystic kidneys are also described. Kapur and Toriello [32] described a brother and sister with multiple congenital anomalies including intestinal malrotation, rectal stenosis and ectopic gastric mucosa in a Meckel diverticulum.

\section{Syndromes featuring intestinal malrotation of uncertain inheritance/aetiology}

Microgastria with limb reduction defects is well-described in the literature, with several case reports [33]. There have been no familial instances, and the aetiology therefore remains uncertain. Two other multiple malformation syndromes have been the subjects of single case reports $[34,35]$.

\section{Intestinal malrotation due to chromosomal imbalance}

Some chromosomal disorders have been associated with malrotation; in these cases, there are usually multiple other abnormalities: other malformations which may contribute to a reduction in life expectancy; restricted growth; dysmorphic facial features, and learning disability, if the child survives. Chromosomal loci with associated phenotype are summarized in the table.

In the light of the phenotype due to deletions at chromosome 16q24.1 discussed above, it is interesting that duplication (trisomy as opposed to monosomy) of the long arm of chromosome 16 is likewise associated with a number of GI tract abnormalities, reviewed in detail by Brisset et al. [36]. These include malrotation, congenital short bowel, imperforate anus and gall bladder agenesis.
Brain, cardiac, genito-urinary tract and vertebral anomalies also occur. The authors attempted to make a genotypephenotype correlation based on chromosome banding; it will be interesting to repeat the exercise on future cases using high-resolution microarray analysis, and to determine whether the FOX transcription factor cluster at 16q24.1 is or is not involved in the aetiology.

Midgut malrotation has been reported in association with ring chromosome 4 [37], a rare structural abnormality in which loss of chromosomal material from both short and long arms of the chromosome occurs. There are fewer than 20 reports of ring chromosome 4 in the literature, of which two have been associated with midgut volvulus [37, 38]. Congenital short bowel [38], duodenal atresia [39] and aplasia of the gall bladder [40] have also been reported in association with this chromosome abnormality.

There are several reports, reviewed in Ref. [41], of deletions of the long arm of chromosome 13 in association with Hirschsprung disease and other GI tract malformations: malrotation, jejunal and ileal atresia, agenesis of mesentery and hypoplastic gallbladder. Heterozygous mutations in $E D N R B$, which is found within the deletion interval, result in Hirschsprung disease, but other GI tract malformations have not been reported in conjunction with $E D N R B$ mutations, suggesting that additional genes within the interval may contribute to the non-Hirschsprung GI malformations in these cases.

\section{A tentative anatomical classification of intestinal malrotation}

Four aetiological groups for intestinal malrotation may tentatively be suggested, comprising abnormalities of leftright patterning, of the dorsal mesentery, of the intestine itself, and of other abdominal contents. Abnormalities of left-right patterning have been covered above. The second category, abnormalities of the dorsal mesentery, is inferred from the fact that a key role for the dorsal mesentery in intestinal rotation has now been established, and secondly from the fact that mutations in FOXF1, a key gene in the establishment of the dorsal mesentery, are associated with intestinal malrotation. The third category is inferred from the observations that abnormalities of the bowel such as congenital short bowel or the presence of multiple atresias are frequently associated with malrotation, and it is likely, though unproven, that the malrotation is a consequence of the bowel abnormality and not the other way around. The fourth category is outside the scope of this review. Briefly, incorrect placement of the intestine or of other organs of the abdominal cavity during embryonic development may lead to intestinal malrotation. Exomphalos, gastroschisis and diaphragmatic hernia are all examples of this. 
Syndromal examples include limb-body wall complex [42] with gastroschisis and a short, non-rotated intestine; and Fryns syndrome [43], in which diaphragmatic hernia and intestinal malrotation both occur.

\section{Concluding remarks}

In this review, we have attempted to collect together reported instances of intestinal malrotation where a genetic approach may shed light on the aetiology of this common gastro-intestinal malformation. The identification of new genes with a role in intestinal development brings benefit both to families, who may be greatly helped by genetic counselling, information about recurrence risk, and possibly pre-natal diagnosis where the disorder is lethal; and to researchers in genetics and developmental biology who seek to understand both normal and abnormal development of the gastro-intestinal tract.

For the geneticist, the traditional approach of disease gene identification by linkage analysis has been and is being supplemented by two new technologies. The first is high-resolution chromosome analysis by DNA microarrays, also termed molecular karyotyping [44, 45]. This has improved the resolution of detection of chromosomal imbalances by orders of magnitude and greatly improved the diagnostic rate for children with a combination of learning difficulties and congenital malformations. The identification of the role of FOXF1 in intestinal malrotation was a direct result of the application of this technology. The second new approach has arisen because of huge improvements in sequencing technology, which now make the sequencing of entire individual genomes feasible, though still currently expensive. This technology can be applied to the detection of mutations in individuals without any prior chromosomal localization. No successful applications of this method have been reported to date, but the next few years are likely to bring exciting results.

It is, therefore, more timely than ever for clinical geneticists to appeal to their colleagues in other specialities, in this case in paediatric gastroenterology and paediatric surgery, for help in the recruitment of suitable families for genetic studies. Enquiry about family history, referral to the local clinical geneticist where there is parental consanguinity or recurrence within a family, and requests for a syndromal diagnosis are all encouraged, and it is the authors' hope that increased cross-talk between our two specialities will bring benefits for all parties-the family, the surgeon, the clinical geneticist and the research community.

Note added to proof Since submission of this manuscript, evidence has emerged that Martinez-Frias syndrome is due to mutations in RFX6.
Smith SB, Qu HQ, Taleb N, Kishimoto NY, Scheel DW, Lu Y, Patch A, Grabs R, Wang J, Lynn FC, Miyatsuka T, Mitchell J, Seerke R, Desir J, Eijnden SV, Abramowicz M, Kacet N, Weill J, Renard ME, Gentile M, Hansen I, Dewar K, Hattersley AT, Wang R, Wilson ME, Johnson JD, Polychronakos C, German MS (2010) Rfx6 directs islet formation and insulin production in mice and humans. Nature 463:775-780.

Acknowledgments CS-S is a recipient of an Intermediate Clinical Fellowship from the Wellcome Trust. The authors gratefully acknowledge additional funding from the Addenbrooke's Charitable Trust and TOFS, the UK support group for patients with oesophageal atresia and tracheo-oesophageal fistula.

Open Access This article is distributed under the terms of the Creative Commons Attribution Noncommercial License which permits any noncommercial use, distribution, and reproduction in any medium, provided the original author(s) and source are credited.

\section{References}

1. McVay MR, Kokoska ER, Jackson RJ, Smith SD (2007) Jack Barney Award. The changing spectrum of intestinal malrotation: diagnosis and management. Am J Surg 6:712-717 (discussion 718-719)

2. Filston HC, Kirks DR (1981) Malrotation-the ubiquitous anomaly. J Pediatr Surg 4(Suppl 1):614-620

3. Torres AM, Ziegler MM (1993) Malrotation of the intestine. World J Surg 3:326-331

4. Stewart DR, Colodny AL, Daggett WC (1976) Malrotation of the bowel in infants and children: a 15 year review. Surgery 6:716720

5. Shaw-Smith C (2006) Oesophageal atresia, tracheo-oesophageal fistula, and the VACTERL association: review of genetics and epidemiology. J Med Genet 7:545-554

6. Mahlapuu M, Ormestad M, Enerback S, Carlsson P (2001) The forkhead transcription factor Foxf1 is required for differentiation of extra-embryonic and lateral plate mesoderm. Development 2:155-166

7. Davis NM, Kurpios NA, Sun X, Gros J, Martin JF, Tabin CJ (2008) The chirality of gut rotation derives from left-right asymmetric changes in the architecture of the dorsal mesentery. Dev Cell 1:134-145

8. Kantor JL (1934) Anomalies of the colon: their Roentgen diagnosis and clinical significance. Radiology 6:651-662

9. Stankiewicz P, Sen P, Bhatt SS, Storer M, Xia Z, Bejjani BA, Ou Z, Wiszniewska J, Driscoll DJ, Bolivar J, Bauer M, Zackai EH, McDonald-McGinn D, Nowaczyk MM, Murray M, Shaikh TH, Martin V, Tyreman M, Simonic I, Willatt L, Paterson J, Mehta S, Rajan D, Fitzgerald T, Gribble S, Prigmore E, Patel A, Shaffer LG, Carter NP, Cheung SW, Langston C, Shaw-Smith C (2009) Genomic and genic deletions of the FOX gene cluster on 16q24.1 and inactivating mutations of FOXF1 cause alveolar capillary dysplasia and other malformations. Am J Hum Genet 84:780-791

10. Maclean K, Dunwoodie SL (2004) Breaking symmetry: a clinical overview of left-right patterning. Clin Genet 6:441-457

11. Smith SL (1972) Familial midgut volvulus. Surgery 3:420-426

12. Beaudoin S, Mathiot-Gavarin A, Gouizi G, Bargy F (2005) Familial malrotation: report of three affected siblings. Pediatr Surg Int 10:856-857

13. Upadhyay V, Hea CM, Matthews RD (2001) Oesophageal atresia: a handshake with malrotation. Eur J Pediatr Surg 6:368-370 
14. Martinez-Frias ML, Frias JL, Galan E, Domingo R, Paisan L, Blanco M (1992) Tracheoesophageal fistula, gastrointestinal abnormalities, hypospadias, and prenatal growth deficiency. Am J Med Genet 3:352-355

15. Chappell L, Gorman S, Campbell F, Ellard S, Rice G, Dobbie A, Crow Y (2008) A further example of a distinctive autosomal recessive syndrome comprising neonatal diabetes mellitus, intestinal atresias and gall bladder agenesis. Am J Med Genet A 13:1713-1717

16. Guttman FM, Braun P, Garance PH, Blanchard H, Collin PP, Dallaire L, Desjardins JG, Perreault G (1973) Multiple atresias and a new syndrome of hereditary multiple atresias involving the gastrointestinal tract from stomach to rectum. J Pediatr Surg 5:633-640

17. Puri P, Guiney EJ, Carroll R (1985) Multiple gastrointestinal atresias in three consecutive siblings: observations on pathogenesis. J Pediatr Surg 1:22-24

18. Daneman A, Martin DJ (1979) A syndrome of multiple gastrointestinal atresias with intraluminal calcification. A report of a case and a review of the literature. Pediatr Radiol 4:227-231

19. Shen-Schwarz S, Fitko R (1990) Multiple gastrointestinal atresias with imperforate anus: pathology and pathogenesis. Am J Med Genet 4:451-455

20. Erez I, Reish O, Kovalivker M, Lazar L, Raz A, Katz S (2001) Congenital short-bowel and malrotation: clinical presentation and outcome of six affected offspring in three related families. Eur $\mathbf{J}$ Pediatr Surg 5:331-334

21. Hamilton JR, Reilly BJ, Morecki R (1969) Short small intestine associated with malrotation: a newly described congenital cause of intestinal malabsorption. Gastroenterology 1:124-136

22. Anneren G, Meurling S, Olsen L (1991) Megacystis-microcolonintestinal hypoperistalsis syndrome (MMIHS), an autosomal recessive disorder: clinical reports and review of the literature. Am J Med Genet 2:251-254

23. Xu W, Orr-Urtreger A, Nigro F, Gelber S, Sutcliffe CB, Armstrong D, Patrick JW, Role LW, Beaudet AL, De Biasi M (1999) Multiorgan autonomic dysfunction in mice lacking the beta2 and the beta4 subunits of neuronal nicotinic acetylcholine receptors. J Neurosci 21:9298-9305

24. van Bever Y, van Hest L, Wolfs R, Tibboel D, van den Hoonaard TL, Gischler SJ (2008) Exclusion of a PAX6, FOXC1, PITX2, and MYCN mutation in another patient with apple peel intestinal atresia, ocular anomalies and microcephaly and review of the literature. Am J Med Genet A 4:500-504

25. Farag TI, al-Awadi SA, el-Badramany MH, Usha R, el-Ghanem M (1993) Second family with "apple peel" syndrome affecting four siblings: autosomal recessive inheritance confirmed. Am J Med Genet 1:119-121

26. Mishalany HG, Najjar FB (1968) Familial jejunal atresia: three cases in one family. J Pediatr 5:753-755

27. Pumberger W, Birnbacher R, Pomberger G, Deutinger J (2002) Duodeno-jejunal atresia with volvulus, absent dorsal mesentery, and absent superior mesenteric artery: a hereditary compound structure in duodenal atresia? Am J Med Genet 1:52-55

28. Stalker HJ, Chitayat D (1992) Familial intestinal malrotation with midgut volvulus and facial anomalies: a disorder involving a gene controlling the normal gut rotation? Am J Med Genet 1:46-47

29. McPherson E, Clemens M (1996) Cleft lip and palate, characteristic facial appearance, malrotation of the intestine, and lethal congenital heart disease in two sibs: a new autosomal recessive condition? Am J Med Genet 1:58-60

30. Poley JR, Proud VK (2008) Hardikar syndrome: new features. Am J Med Genet A 19:2473-2479

31. Rosser EM, Mann NP, Hall CM, Winter RM (1996) Serpentine fibula syndrome: expansion of the phenotype with three affected siblings. Clin Dysmorphol 2:105-113
32. Kapur S, Toriello HV (1991) Apparently new MCA/MR syndrome in sibs with cleft lip and palate and other facial, eye, heart, and intestinal anomalies. Am J Med Genet 4:423-425

33. Cunniff C, Williamson-Kruse L, Olney AH (1993) Congenital microgastria and limb reduction defects. Pediatrics 6:1192-1194

34. Maegawa GH, Chitayat D, Blaser S, Whyte H, Thomas M, Kim P, Kim J, Taylor G, McNamara PJ (2006) Duodenal and biliary atresia associated with facial, thyroid and auditory apparatus abnormalities: a new mandibulofacial dysostosis syndrome? Clin Dysmorphol 4:191-196

35. Kumar D (1999) A case of lateral facial clefts with Fallot tetralogy, duodenal stenosis and intestinal malrotation: a new multiple congenital anomaly syndrome? Clin Dysmorphol 1:19-21

36. Brisset S, Joly G, Ozilou C, Lapierre JM, Gosset P, LeLorc'h M, Raoul O, Turleau C, Vekemans M, Romana SP (2002) Molecular characterization of partial trisomy 16q24.1-qter: clinical report and review of the literature. Am J Med Genet 4:339-345

37. Balci S, Engiz O, Aktas D, Vargel I, Beksac MS, Mrasek K, Vermeesch J, Liehr T (2006) Ring chromosome 4 and WolfHirschhorn syndrome (WHS) in a child with multiple anomalies. Am J Med Genet A 6:628-632

38. Hou JW, Wang TR (1996) Amelia, dextrocardia, asplenia, and congenital short bowel in deleted ring chromosome 4. J Med Genet 10:879-881

39. Halal F, Vekemans M (1990) Ring chromosome 4 in a child with duodenal atresia. Am J Med Genet 1:79-82

40. Kocks A, Endele S, Heller R, Schroder B, Schafer HJ, Stadtler C, Makrigeorgi-Butera M, Winterpacht A (2002) Partial deletion of $4 p$ and $4 q$ in a fetus with ring chromosome 4 : phenotype and molecular mapping of the breakpoints. J Med Genet 5:E23

41. Shanske A, Ferreira JC, Leonard JC, Fuller P, Marion RW (2001) Hirschsprung disease in an infant with a contiguous gene syndrome of chromosome 13. Am J Med Genet 3:231-236

42. Cusi V, Torrents M, Vila J, Antich J, Carrera JM (1996) Limb body wall complex: analysis of eight fetuses. Birth Defects Orig Artic Ser 1:165-170

43. Slavotinek A, Lee SS, Davis R, Shrit A, Leppig KA, Rhim J, Jasnosz K, Albertson D, Pinkel D (2005) Fryns syndrome phenotype caused by chromosome microdeletions at $15 \mathrm{q} 26.2$ and 8p23.1. J Med Genet 9:730-736

44. Shaw-Smith C, Redon R, Rickman L, Rio M, Willatt L, Fiegler H, Firth H, Sanlaville D, Winter R, Colleaux L, Bobrow M, Carter NP (2004) Microarray based comparative genomic hybridisation (array-CGH) detects submicroscopic chromosomal deletions and duplications in patients with learning disability/ mental retardation and dysmorphic features. J Med Genet 4:241248

45. Ledbetter DH (2008) Cytogenetic technology-genotype and phenotype. N Engl J Med 16:1728-1730

46. Gargiulo A, Auricchio R, Barone MV, Cotugno G, Reardon W, Milla PJ, Ballabio A, Ciccodicola A, Auricchio A (2007) Filamin $\mathrm{A}$ is mutated in $\mathrm{X}$-linked chronic idiopathic intestinal pseudoobstruction with central nervous system involvement. Am J Hum Genet 4:751-758

47. Bamford RN, Roessler E, Burdine RD, Saplakoglu U, dela Cruz J, Splitt M, Goodship JA, Towbin J, Bowers P, Ferrero GB, Marino B, Schier AF, Shen MM, Muenke M, Casey B (2000) Loss-of-function mutations in the EGF-CFC gene CFC1 are associated with human left-right laterality defects. Nat Genet 3:365-369

48. Gebbia M, Ferrero GB, Pilia G, Bassi MT, Aylsworth A, Penman-Splitt M, Bird LM, Bamforth JS, Burn J, Schlessinger D, Nelson DL, Casey B (1997) X-linked situs abnormalities result from mutations in ZIC3. Nat Genet 3:305-308

49. Ware SM, Peng J, Zhu L, Fernbach S, Colicos S, Casey B, Towbin J, Belmont JW (2004) Identification and functional 
analysis of ZIC3 mutations in heterotaxy and related congenital heart defects. Am J Hum Genet 1:93-105

50. Watanabe Y, Benson DW, Yano S, Akagi T, Yoshino M, Murray JC (2002) Two novel frameshift mutations in NKX2.5 result in novel features including visceral inversus and sinus venosus type ASD. J Med Genet 11:807-811

51. Kosaki R, Gebbia M, Kosaki K, Lewin M, Bowers P, Towbin JA, Casey B (1999) Left-right axis malformations associated with mutations in ACVR2B, the gene for human activin receptor type IIB. Am J Med Genet 1:70-76

52. Kosaki K, Bassi MT, Kosaki R, Lewin M, Belmont J, Schauer G, Casey B (1999) Characterization and mutation analysis of human
LEFTY A and LEFTY B, homologues of murine genes implicated in left-right axis development. Am J Hum Genet 3:712-721

53. Dallaire L, Perreault G (1974) Hereditary multiple intestinal atresia. Birth Defects Orig Artic Ser 4:259-264

54. Balci S, Senocak ME, Derbent M (2003) Triphalangeal thumb in a case of VACTERL-hydrocephalus association. Genet Couns $2: 257-258$

55. Masuno M, Ishii T, Tanaka Y, Ohyama M, Kawataki M, Kimura J, Imaizumi K, Kuroki Y (2000) De novo trisomy 16p11.2-qter: report of an infant. Am J Med Genet 5:308-310

56. Hamburger V, Hamilton HL (1992) A series of normal stages in the development of the chick embryo. 1951. Dev Dyn 195:231-272 